\title{
COMPARISON BETWEEN BABY LED WEANING AND TRADITIONAL SPOON-FEEDING ON IRON STATUS AND GROWTH IN BREASTFED INFANTS
}

\author{
Meta Herdiana Hanindita $^{1^{*}}$, Nur Aisiyah Widjaja1, Roedi Irawan', Boerhan \\ Hidayat $^{1}$ \\ ${ }^{I}$ Department of Child Health, Dr. Soetomo Hospital Faculty of Medicine, Universitas Airlangga, \\ Surabaya, Indonesia \\ *hanindita.meta@gmail.com \\ https://doi.org/10.34302/crpifst/2019.11.5.14 \\ Article history: \\ Received: \\ 9 March 2019 \\ Accepted: \\ 20 September 2019 \\ Keywords: \\ Complementary feeding; \\ Baby-led weaning; \\ Faltering growth; \\ Iron deficiency anemia

\section{ABSTRACT} \\ Background: The current guideline recommends infants are initially \\ offered smoothly pureed foods, known as the traditional method of spoon \\ feeding. Currently, an alternative method known as 'baby-led weaning' \\ (BLW) has been really popular. With BLW, infants are allowed to self- \\ feed family foods in their whole form instead special-prepared foods. \\ Infants following BLW may be at increased risk of faltering growth. \\ Objective: To compare traditional and BLW methods in the risk of iron \\ deficiency anemia (IDA) and growth faltering of breastfed infants. \\ Methods: A cross-sectional study was undertaken in $9-15$ months \\ breastfed infants admitted to Bedah Hospital Surabaya from August - \\ October 2017. Exclusion criteria were infants suffering from chronic \\ conditions. Biochemical assessment of Haemoglobin (Hb), Serum \\ Transferrin (ST) and Serum Ferritin (SF) was measured. Diagnosis of IDA \\ and growth chart interpretation was made based on WHO criteria. \\ Results: Out of all, 12/30 boys and 15/30 following BLW. Mean age was \\ $12.6 \pm 2.14$ months old. Mean Hb level, ST level and SF in BLW group was \\ $10.9 \pm 0.55 \mathrm{~g} / \mathrm{dl}, 11.6 \pm 7.13 \%, 19.1 \pm 18.40 \mathrm{ug} / \mathrm{dl}$ prospectively, while in the \\ traditional group were $12.5 \pm 0.75 \mathrm{~g} / \mathrm{dl}, 24.6 \pm 7.92 \%, 57.6 \pm 18.78 \mathrm{ug} / \mathrm{dl}$ \\ prospectively. IDA was higher in BLW group than in the traditional group. \\ $(13 / 15$ vs $3 / 15$, OR $26.00095 \%$ CI 3.686-183.418, p <0.001). Underweight \\ was higher in BLW. (13/15 vs 3/15, OR 26.000 95\%CI 3.686-183.418, p \\ $<0.001)$. Stunted were higher in BLW (2/15 vs none, OR $1.66795 \%$ CI \\ 1.103-2.519. $\mathrm{p}=0.017$ ). \\ Conclusion: In breastfed infants, those who were following BLW are in \\ higher risk of IDA, underweight and stunted than traditional spoon feeding.
}

\section{Introduction}

The current guideline of the World Health Organization recommends that infants are initially offered smoothly pureed foods, and gradually increased food consistency and variety as the infant gets older, adapting to the infant's requirements and abilities. The guideline also recommends practicing responsive feeding, specifically feed infants directly and assist older children when they feed themselves. This is known as the traditional method of spoonfeeding (WHO, 2001). Over the last 10 years, an alternative method known as 'baby-led weaning' (BLW) has been really popular in Indonesia.

Baby-led weaning is a method for introducing complementary foods in which 
the infant feeds themselves hand-held foods or finger foods instead of being spoon-fed by an adult. Infants following BLW share family food and are offered breast milk on demand until they wean. (Cameron et al., 2012; Brown et al., 2017)

Baby-led weaning was introduced with the publication of the book of Baby-Led Weaning by Gill Rapley and Tracey Murkett. It has been suggested that BLW may encourage greater acceptance of foods with a variety of textures and flavors and that this may result in higher intakes of "healthier" foods such as vegetables and unprocessed foods as the child grows, so it could lower the risk of obesity. In BLW, infants share family food and meal times. The food is offered as "graspable" pieces that they can pick up and they learn to feed themselves. The infant is in control of exactly what and how much they eat, They never hurried or forced to eat food. Combined method of BLW and traditional spoon-feeding is not defined as BLW (Rapley, 2008).

Weaning period is a peak period for faltering in a child's growth. (Abeshu et al., 2016) Infants following BLW may be at increased risk of growth faltering, based on the assumption that not all infants will have the motor skills to feed themselves the amount of food they require, and that many of the first foods offered will be low in energy and iron.

\section{Materials and methods}

\subsection{Materials}

All breastfed infants between 9 months old to 15 months old were prospectively enrolled. Exclusion criteria included chronic conditions such as cerebral palsy, congenital deformities and chromosomal disorders. Infants with urinary tract infection, hypothyroid, and tuberculosis were also excluded.

\subsection{Methods}

This study was approved by the institutional review board of the Bedah Hospital Surabaya. The present study was carried out in the Outpatient Clinic Bedah
Hospital Surabaya, during the period from August 2017 until October 2017. Based on the anamnesis, we classified all the subjects into 2 groups based on their feeding methods, the BLW group and the traditional group. Assessment of Haemoglobin ( $\mathrm{Hb})$, Serum Transferrin (ST) and Serum Ferritin (SF) was measured, as well body weight and body length. Diagnosis of IDA and growth anthropometry was interpreted based on WHO criteria. SPSS for Mac was used for analyses. To compare continuous variables, we used a two-sample $t$ test or Mann- Whitney rank sum test, and to compare categorical variables we used the Chi-square or Fisher's exact test, as indicated.

\section{Results and discussions}

There were 30 infants included in the study. Of these, 12 infants were boys. All the infants started the complementary feeding at 6 months old. There was 15 infants who were following BLW, and there was 15 infants who were following traditional spoon-feeding method. Mean age was 12.6 \pm 2.14 months old. There was no significant difference between two groups with respect to age or sex (see Table 1). There was significant difference between two groups on $\mathrm{Hb}$ level, Serum Transferrin and Serum Ferritin $(\mathrm{P}<0.001)$. Iron Deficiency Anemia was higher in BLW group than in the traditional group. (13/15 vs $3 / 15$, OR 26.00 95\%CI 3.686-183.418, $\mathrm{p}<0.001$ ) (see Table 2).

\subsection{Comparison on Iron Status}

Iron Deficiency Anemia was higher in BLW group than in the traditional group. $(13 / 15$ vs $3 / 15$, OR 26.00 95\%CI 3.686$183.418, \mathrm{p}<0.001)$.

\subsection{Comparison on Growth Status}

Underweight was higher in BLW group then in the traditional group. (13/15 vs $3 / 15$, OR 26.00 95\%CI 3.686-183.418, p <0.001). Severe underweight was higher in BLW group then in the traditional group. (2/15 vs $0 / 15)$. Stunted were higher in BLW group (2/15 vs none, OR 1.67 95\%CI 1.103-2.519. $\mathrm{p}=0.017$ ) than in the traditional group, meanwhile wasted 
was higher in BLW group then in the traditional group (11/15 vs $2 / 15)$.

To date, there are limited researches about BLW. Our study showed there was no difference noted with both groups with respect to gender and age. This was in line with some previous study (Morison et al., 2016; Cameron et al., 2013).

A significant difference was noted in iron status between the two groups $(\mathrm{P}<0.001)$. There was no consideration about iron status before study. Until now, there were no studies examining iron status in infants following BLW. But, there was a study revealed that infants following BLW appeared to have significantly lower intakes of iron, zinc and vitamin B12 (Morison et al., 2016). This was consistent with another study revealed that infants following BLW ate more fruits and vegetables which were low-iron foods while the infants following traditional spoon-feeding eat more baby rice cereal (Cameron et al., 2013).

Food presentation significantly influences food preferences (Blossfeld et al., 2007), so it is possible that differences in the presentation of foods between the two groups impacted on preferences. Meat may be easier to eat when pureed and spoon-fed (Morison et al., 2016). This can be explained by the fact that infants' early chewing is a primitive updown munching pattern (Morris et al., 2000; Rudolph et al., 2002). For small pieces of soft foods, this pattern may be adequate. But for hard foods such as meat or strips, it is inadequate (Morris et al., 2000). BLW may not be suitable for age and infant's feeding skill development.
Our study noted a significant difference in growth status between both groups. Infants following BLW were at increased risk to have underweight, stunted and wasted. Consistent with this, some previous studies also showed underweight was higher in infants following BLW compared to those who were following traditional spoon- feeding (Townsend et al., 2012; Brown et al.,2015). According to one study in the United Kingdom which compared body weight for age in infants following BLW and infants following traditional spoonfeeding. For the BLW group, 86.5\% were of normal weight, $8.1 \%$ overweight and $5.4 \%$ underweight. In comparison, $78.3 \%$ of those in the traditional spoon-feeding group were normal weight, $19.2 \%$ overweight and $2.5 \%$ underweight (Brown et al., 2015).

Mothers following BLW method estimated that their babies ate more milk feeds and less solid food compare to those following a traditional spoon-feeding. This may provide inadequate nutrient intake such as energy and iron requirements for infants from 6 months of age onwards (Brown et a1., 2015).

Since in BLW approach, the infants are in full control to eat, there are some risks of inadequate intake. When the infants do not have interest in eating, when foods of inappropriate consistency are offered, and infants with poor self-feeding skills will nou able to have enough foods to meet their needs for rapid growth. This risk of inadequate energy and nutrient intake could lead to failure to thrive.

Table 1. Characteristic of samples

\begin{tabular}{|l|l|l|l|}
\hline Variable & BLW $(\mathbf{n}=\mathbf{1 5})$ & Traditional $(\mathbf{n}=\mathbf{1 5})$ & $\mathbf{P}$ \\
\hline Age $(\mathrm{mo})$ & $13 \pm 1.78$ & $12.2 \pm 2.30$ & 0.396 \\
$12.6 \pm 2.14$ & & & \\
\hline Sex & & & 0.143 \\
Boys & 12 & 18 & \\
Girl & 18 & 12 & \\
\hline
\end{tabular}




\begin{tabular}{|l|l|l|l|}
\hline Iron Status & & & \\
$\mathrm{Hb}(\mathrm{g} / \mathrm{dl})$ & $10.9 \pm 0.55$ & $12.5 \pm 0.75$ & $<0.001^{*}$ \\
$\mathrm{ST}(\%)$ & $11.6 \pm 7.13$ & $24.6 \pm 7.92$ & $<0.001^{*}$ \\
$\mathrm{SF}(\mathrm{ng} / \mathrm{ml})$ & $19.1 \pm 18.40$ & $57.6 \pm 18.78$ & $<0.001^{*}$ \\
\hline
\end{tabular}

Table 2. Logistic Regression Analysis

\begin{tabular}{|l|l|l|l|}
\hline & Odds Ratio & P & 95\% CI \\
\hline $\begin{array}{l}\text { Iron Deficiency } \\
\text { Anemia }\end{array}$ & 26.00 & $<0.001$ & $3.686-183.418$ \\
\hline Underweight & 26.00 & $<0.001$ & $3.686-183.418$ \\
\hline Stunted & 1.67 & 0.017 & $1.103-2.519$ \\
\hline
\end{tabular}

* Chi-square test

Table 3. Comparison of growth parameter between two groups

\begin{tabular}{|l|c|c|}
\hline Growth Parameter & BLW & Traditional \\
\hline Weight for age & 2 & 12 \\
Normal & 11 & 3 \\
Underweight & 2 & 0 \\
Severe underweight & & \\
\hline Length for age & 9 & 15 \\
Normal & 6 & 0 \\
Stunted & & \\
Weight for length & 4 & 13 \\
Normal & 11 & 2 \\
Wasted
\end{tabular}

\section{Conclusions}

Those who were following BLW are in higher risk of IDA, underweight and stunted than those who were fed traditionally. There are still some controversies of BLW that need further research.

\section{References}

Abeshu MA., Lelisa A., Geleta B. (2016) Complementary feeding: Review of recommendations, feeding practices, and adequacy of fomemade complementaryfood preparations in developing countries. Lessons from Ethiopia. Frontier Nutrition, 17, 3,41.

Blossfeld I., Collins A., Kiely M., Delahunty C. (2007) Texture preferences of 12- month-old infants and the role of early experiences. Food Quality and Preference, 18(2), 396-404.

Brown A., Jones SW., Rowan H. (2017) Baby-led weaning: the evidence to date. Current Nutrition Reports, 6(2), 148-56.

Brown A., Lee MD. (2015) Early influences on child-satiety-responsiveness: the role of weaning style, Pediatric Obesity, 10(1), 57-66.
Cameron S., Taylor R., Heath AL. Parent- led or baby-led? Associations between complementary feeding practices and healthrelated behaviours in a survey of New Zealand families. BMJ Open, 3, 1- 9.

Cameron SL., Health AL., Taylor RW. (2012) How feasible is baby-led weaning as an approach to infant feeding? A review of the evidence. Nutrients, 4, 1575-609. Morison BJ., Taylor RW., Haszard JJ., Schramm CJ., Erickson LW., Fangupo LJ., Fleming EA., Luciano A., Heath AM. (2016) How different are baby-led weaning and conventional complementary feeding? A cross- sectional study of infants aged 6-8 months. BMJ Open, 6(5), 1-11.

Morris E., Klein D. (2000) Pre-feeding skills, 2nd ed. USA: Therapy skills builders.

Rapley G., Murkett T. (2008) Baby-led weaning: Helping your baby to love good food. (1st ed). London:Vermillion.

Rudolph C., Link T. (2002) Feeding disorders in infants and children. Pediatric Clinics of North America, 49, 97-112.

Townsend E., Pitchford NJ. (2012) Baby knows 
best? The impact of weaning style on food preferences and body mass index in early childhood in a case- controlled sample. $B M J$ Open, 2(1), 1-6.

World Health Organization. (2001) Guiding Principles for Complementary Feeding of the Breastfed Child. Geneva: WHO Press. 